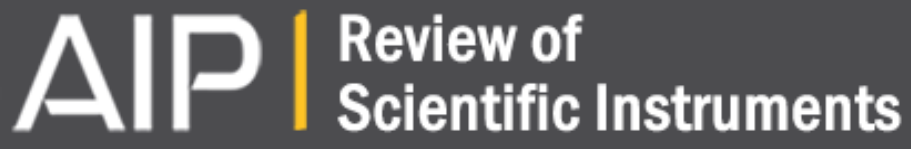

\section{High-pressure phase equilibria with compressed gases}

Wei Ren and Aaron M. Scurto

Citation: Review of Scientific Instruments 78, 125104 (2007); doi: 10.1063/1.2814025

View online: http://dx.doi.org/10.1063/1.2814025

View Table of Contents: http://scitation.aip.org/content/aip/journal/rsi/78/12?ver=pdfcov

Published by the AIP Publishing

\section{Articles you may be interested in}

Phase equilibrium and metastability of liquid benzene at high pressures

J. Chem. Phys. 124, 204505 (2006); 10.1063/1.2198808

Isomolar semigrand ensemble molecular dynamics: Development and application to liquid-liquid equilibria J. Chem. Phys. 122, 054504 (2005); 10.1063/1.1839172

Binary phase behavior and aggregation of dilute methanol in supercritical carbon dioxide: A Monte Carlo simulation study

J. Chem. Phys. 121, 1525 (2004); 10.1063/1.1763842

High-pressure light scattering apparatus to study pressure-induced phase separation in polymer solutions Rev. Sci. Instrum. 69, 1463 (1998); 10.1063/1.1148782

Light scattering investigations in a ternary liquid mixture: Quest for a critical inflection point

J. Chem. Phys. 107, 8020 (1997); 10.1063/1.475065






\title{
High-pressure phase equilibria with compressed gases
}

\author{
Wei Ren and Aaron M. Scurto ${ }^{\text {a) }}$ \\ Department of Chemical and Petroleum Engineering, University of Kansas, Lawrence, Kansas 66045, USA \\ and NSF-ERC Center for Environmentally Beneficial Catalysis, University of Kansas, Lawrence, \\ Kansas 66045, USA
}

(Received 25 September 2007; accepted 28 October 2007; published online 13 December 2007; publisher error corrected 4 February 2008)

\begin{abstract}
An apparatus is described that is capable of determining high-pressure vapor-liquid equilibrium, liquid-liquid equilibrium, solid-liquid-vapor equilibrium, vapor-liquid-liquid equilibrium, and mixture critical points and transitions. The device is capable of temperatures to $150{ }^{\circ} \mathrm{C}$ and pressures to 300 bars (higher with slight modifications). The construction and operation are described in detail and do not require the use of mercury. This method requires very low sample volumes and no analytical equipment nor system-specific calibration. The apparatus was verified by comparison with literature data for the decane- $\mathrm{CO}_{2}$ mixture and $\mathrm{CO}_{2}$-ionic liquid [1-hexyl-3-methyl-imidazolium bis(trifyl)imide)] systems. The experimental data have excellent agreement with the literature data that used different experimental methods. A rigorous error analysis of the system is also presented. (C) 2007 American Institute of Physics.
\end{abstract}

[DOI: 10.1063/1.2814025]

\section{INTRODUCTION}

Many scientific and industrial processes are conducted with compressed gases at elevated pressures: $\mathrm{CO}_{2}$-enhanced oil recovery and coal bed methane production, ${ }^{1}$ natural product extraction, ${ }^{2,3}$ nanoparticle formation, ${ }^{4}$ selective particle precipitation with gaseous and supercritical $\mathrm{CO}_{2}{ }^{5,6}$ etc. Phase equilibrium is fundamental to all of these applications. For instance, with gas-liquid biphasic reaction mixtures, which includes gas-expanded liquids, ${ }^{7,8}$ phase equilibria play a key role in the understanding and determination of reaction kinetics. The equilibrium solubilities (chemical potentials) provide the driving force for interphase mass transfer. In addition, phase equilibria data allow theoretical development of high-pressure and near-critical phenomena. ${ }^{9-11}$

Several experimental methods can be used to measure high-pressure phase equilibria. These methods are generally divided into two categories: analytical and synthetic approaches. ${ }^{12}$ For analytical methods, samples are typically taken from each phase and analyzed using various detection methods, such as gas chromatography (GC), high-pressure liquid chromatography (HPLC), NMR, IR, etc. The synthetic method is a direct approach in a closed system. A certain concentration of mixture is loaded and the points of phase transition (temperature, pressure, etc.) are observed. Often in the synthetic methods, liquid mercury is used as a pressure transfer medium that has no or negligible solubility in the compressed gas. ${ }^{13,14}$ Reducing the possibility of worker exposure to mercury would be advantageous.

The apparatus introduced in this paper belongs to the category of the synthetic method, based on a material balance. This apparatus is capable of measuring vapor-liquid (VLE), liquid-liquid (LLE), vapor-liquid-liquid (VLLE), and

${ }^{\text {a)} E l e c t r o n i c ~ m a i l: ~ a s c u r t o @ k u . e d u . ~}$ solid-liquid-vapor (SLV) equilibria, in addition to viewing general high-pressure phase behavior (pressure and temperature of transitions). The apparatus is most commonly used to determine the vapor-liquid equilibrium (gas solubility) of compressed gases, such as carbon dioxide, in single component or multicomponent liquids. Many properties may be obtained including concentration (mass fraction, mole fraction, molarity, molality, etc.) of gases in liquids, liquid molar volume and density, the induced volume expansion of the gasexpanded liquids, etc. SLV data and VLLE data can also be obtained by slightly different procedures. Quantitative solubility measurements are limited to single component gases, and liquids or liquid mixtures with lower volatilities than the compressed gas. This work will describe in detail the setup and operation of the apparatus. In addition, a rigorous error analysis has been performed to quantify the inherit error at any condition ( $T, P$, volume, composition, etc.).

\section{OVERVIEW OF APPARATUS AND PRINCIPLE OF OPERATION}

This apparatus mainly consists of a high-pressure view cell (equilibrium cell), high-pressure and precision syringe pump filled with the desired gas, a water bath, and accessories to measure the temperature and pressure (see Fig. 1). A spreadsheet is developed to calculate the solubility, density of the liquid solution, molar volume, volume expansion, and molarity. These calculations are based on the mass balance by determining the amount of gas delivered from the pump, the moles/mass of gas in the headspace above the liquid, and in the tubing/lines to the equilibrium cell. This method can yield high resolution of solubility data (often better than \pm 0.001 ), pressure with accuracy of \pm 0.2 bar, temperature of 


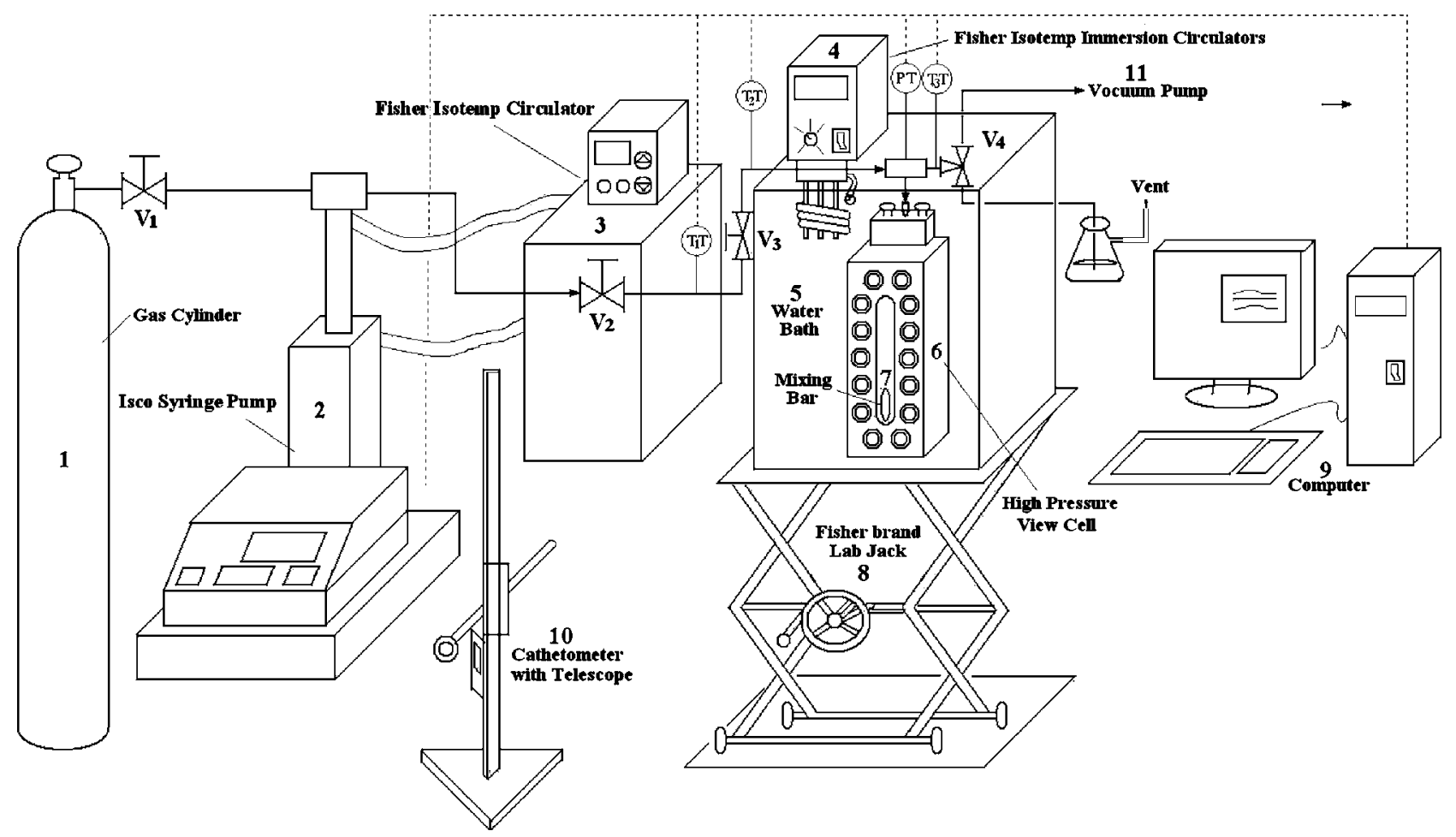

FIG. 1. Diagram of experimental apparatus. (1) Gas cylinder; (2) syringe pump; (3) heater/circulator; (4) immersion heater/circulator; (5) water bath; (6) high-pressure view cell; (7) mixing bar; (8) laboratory jack; (9) computer; (10) cathetometer with telescope; (11) vacuum pump.

$\pm 0.01{ }^{\circ} \mathrm{C}$, density up to $\pm 0.4 \%$, and volume expansion to $\pm 0.05 \%$. In addition, there is no need for analytical methods nor calibration for each system of interest.

Some of the initial concepts of this apparatus were devised by Kurata and Kohn, here at the University of Kansas, over 50 years ago. ${ }^{15}$ Some modifications were introduced by Kohn and Huie, ${ }^{16}$ and Brennecke and Scurto ${ }^{17}$ at the University of Notre Dame. Luks ${ }^{18}$ at the University of Tulsa used a similar apparatus as Kohn's. However, these devices utilize mercury for pressure transfer to the gas and to reduce the gas volume inside the pressure gauges. The present apparatus uses a similar mass balance concept, but simplifies the initial design, eliminates the use of mercury, provides a robust equilibrium cell, and improves the accuracy, operability, and ease of data acquisition. In addition, procedures for the measurement of other types of phase equilibria are introduced.

\section{EXPERIMENTAL PRINCIPLES}

The phase equilibria data are obtained based on a mass balance. The main assumption asserts that the pressure of the compressed gas is much greater than the vapor pressure of the liquid, and/or the vapor phase composition of the liquid component is much less $(\ll 10 \%$ mole) than the compressed gas. The mass of gas in the liquid phase is calculated by subtracting the mass of gas in the lines and headspace above the liquid from the total mass of gas injected into the system. The mass balance equation of the gas is

$$
\begin{aligned}
& m_{g}=m_{\text {pump }}-m_{\text {lines }}-m_{\text {headspace }}+m_{\text {lines }}^{0}+m_{\text {headspace }}^{0}, \\
& m_{\text {pump }}=\Delta V_{\text {pump }} \rho\left(T_{\text {pump }}, P_{\text {pump }}\right), \\
& m_{\text {lines }}=V_{\text {lines }} \rho\left(T_{\text {lines }}, P\right)
\end{aligned}
$$

$$
\begin{aligned}
& m_{\text {headspace }}=\left(V_{\text {cell }}-V_{l}\right) \rho(T, P), \\
& m_{\text {lines }}^{0}=V_{\text {lines }} \rho\left(T_{\text {lines }}, P^{0}\right), \\
& m_{\text {headspace }}^{0}=V_{\text {headspace }} \rho\left(T, P^{0}\right),
\end{aligned}
$$

where $m_{g}$ is the mass of the gaseous component in the liquid, $m_{\text {pump }}$ is the mass of the gas injected into the system, which is the product of the volume of the gas displaced by the metering pump $\left(\Delta V_{\text {pump }}\right)$ at constant temperature and pressure, and the density of the gas in the pump $\left[\rho\left(T_{\text {pump }}, P_{\text {pump }}\right)\right] . m_{\text {lines }}$ is the mass of the gas in the lines connecting the pump to the equilibrium cell. It is determined by multiplying the volume of the lines $\left(V_{\text {lines }}\right)$ by the density of the gas in the lines $\left[\rho\left(T_{\text {lines }}, P\right)\right]$ at the system equilibrium pressure $P$ and at a relatively high temperature; the temperature is usually set higher than the critical point of the gas to eliminate gas condensing in the lines which could decrease the accuracy of the liquid solubility data (see error analysis in the supplemental file). ${ }^{32} m_{\text {headspace }}$ is the mass of the gas in the headspace, which is calculated in the same way as $m_{\text {lines }}$ except at the system temperature $T$. The volume of the headspace is the difference between the liquid volume $\left(V_{l}\right)$ and the total cell volume $\left(V_{\text {cell }}\right)$. Since the liquid volume generally expands with the gas pressure, the headspace volume also decreases with the pressure/composition. As the apparatus is purged with the compressed gas of interest to remove any air or other capping gases, some of the gas is initially in the lines and headspace. $m_{\text {lines }}^{0}$ is the mass of the gas in the lines after venting the system. $m_{\text {headspace }}^{0}$ is the mass of the gas in the headspace initially in the system after venting. For work at moderate to high pressures ( $>10$ bars), the initial solubility of the gas in the liquid at atmospheric pressure $P^{0}$ 
will be negligible compared at higher pressures, e.g., for $\mathrm{CO}_{2}$. However, for gases that are highly soluble in liquids at atmospheric pressure (for instance, hydrofluorocarbons, etc.), a vacuum may be applied to establish initial conditions with low solubility in the liquid.

The mole fraction of the gas in the liquid $x_{g}$ then becomes

$$
x_{g}=\frac{n_{g}}{n_{l}+n_{g}}=\frac{m_{g} / M_{g}}{m_{l} / M_{l}+m_{g} / M_{g}},
$$

where $n_{g}$ is the moles of the gaseous component, $n_{l}$ is the moles of the liquid component, $M_{g}$ is the molecular weight of the gas, $m_{l}$ is the mass of the liquid sample, and $M_{l}$ is the molecular weight of the liquid: The mass fraction of the gas $i$ in the liquid $\omega_{g}$ is

$$
\omega_{g}=\frac{m_{g}}{m_{g}+m_{l}} .
$$

Molar volume of the liquid mixture $\underline{V}$ is computed from the liquid volume and the moles of the gas and liquid mixture:

$$
\underline{V}=\frac{V_{l}}{\left(n_{g}+n_{l}\right)},
$$

where $V_{l}$ is the volume of the liquid (usually in $\mathrm{ml} / \mathrm{cm}^{3}$ ); volume expansion accounts for the volume change before and after dissolving the gas in the liquid:

$$
\frac{\Delta V}{V_{0}}=\frac{V_{l}-V_{0}}{V_{0}},
$$

where $\Delta V$ is the volume difference between pure liquid volume and expanded liquid volume; $V_{0}$ is the initial liquid volume at the system temperature. Molality $[\mathrm{m}]$ (braces to distinguish from mass, $m$ ) can be calculated from the definition:

$$
[m]=\frac{1000 \times n_{g}}{m_{l}} .
$$

Molarity $M$ is expressed as

$$
M=\frac{1000 \times n_{g}}{V_{l}},
$$

where the unit of $m_{l}$ is in grams, and $V_{l}$ is in milliliters.

\section{Density calculations}

Density calculations of the pure gas must have a high accuracy. While experimental data may be used or interpolated, ultraaccurate equations of state are highly useful. Here, densities are determined from REFPROP database (version 8.0). ${ }^{19}$ REFPROP includes three models to calculate the thermodynamic properties of pure fluids: equations of state explicit in Helmholtz energy, the modified Benedict-WebbRubin equation of state, and an extended corresponding state (ECS) model. As an example, the database uses the ultraaccurate Span-Wagner equation of state ${ }^{19,20}$ for $\mathrm{CO}_{2}$. REFPROP provides a dynamic link library (“.dll”) that allows incorporation in a broad variety of software applications, such as EXCEL, VISUAL BASIC \& C, MATLAB, LABVIEW, etc.

\section{APPARATUS DETAILS}

This setup mainly includes an Isco, Inc. 100 DM syringe pump with a 5000 psi externally mounted pressure transducer of $0.1 \%$ full scale accuracy, a high-pressure view cell, and a computer data acquisition system. The pump has a volume resolution of $9 \mathrm{nl}$. The accessories include a Fisher, Inc. Isotemp circulator, model 3016 with $0.01{ }^{\circ} \mathrm{C}$ resolution, to maintain the temperature of the pump, and a water bath and an immersion circulator (Haake DC30/DL3) to maintain the water bath temperature with temperature stability greater than $\pm 0.1 \mathrm{~K}$. A platform jack (Fisher Lab-Jack) allows the bath to be lowered away from the equilibrium cell which is mounted from above. An Eberbach 5160 cathetometer with telescope is used to read the height of the liquid level to a resolution of $0.01 \mathrm{~mm}$ and accuracy of $\pm(0.02+0.00005 \mathrm{~L})$, where $L$ represents the length from the starting point of the measurement to the given position ( $\mathrm{mm}$ ). The gas lines are heated using fiberglass covered heating tape, controlled by two variable AC transformers, Staco Energy ${ }^{\circledR}$ model 3PN1010B. The line temperatures are usually maintained above the critical point of the gas; for instance, with $\mathrm{CO}_{2}$ $\left(T_{c}=31.1{ }^{\circ} \mathrm{C}\right) \sim 60{ }^{\circ} \mathrm{C}$. In order to prevent the heat from dissipating to the surroundings, a fiberglass cloth tape insulation is used. The line temperatures are measured by T-type thermocouples with an accuracy of $\pm 0.5^{\circ} \mathrm{C}$. A Measurement Computing, Inc. USB-TC is used to interface the thermocouples to the data acquisition system. The pump temperature is measured by an Ertco-Eutechnic 5 digital thermister, model 4400 , with an accuracy of at least $\pm 0.01{ }^{\circ} \mathrm{C}$ in the range of $0-100{ }^{\circ} \mathrm{C}$. The pressure of the cell is measured by a 5000 psi Heise DXD Series 3711 precision digital pressure transducer which has an accuracy of $\pm 0.02 \%$ full scale (FS) with ranges of $10-30{ }^{\circ} \mathrm{C}, \pm 0.04 \%$ FS $0-50{ }^{\circ} \mathrm{C}$ and $\pm 0.05 \%$ FS $-10-70{ }^{\circ} \mathrm{C}$. The pressure transducer interfaces with the data acquisition system by a serial port converter. LABVIEW 8.2 software is used for the data acquisition. The temperature of the lines, the pressure of the cell and the lines, the pump information including volume, flow rate, and pressure are monitored and logged at $60 \mathrm{~s}$ intervals. The data sampling rate is adjustable from 30 to $240 \mathrm{~s}$. The gas line tubing uses small diameter $(1 / 16$ in. outside diameter, 0.006 in. inside diameter) HIP tubing to minimize the volume of the lines. The tubing connections use HIP 1/16 in. taper seal fittings (AF1) and HIP 15-24AF1 316SS tee. All valves are HIP 15-11AF1 316SS type except the output valve, which uses the three way Swagelok® valve (SS$41 \mathrm{XS} 1$ ), and is connected from the output line to a vacuum pump and to a $125 \mathrm{ml}$ Pyrex vent filtering flask with a No. 4 rubber stopper to remove any organic compounds from the venting gas. The vent filtering flask uses 1/16 in. Nalgene 180 PVC nontoxic autoclavable $3 / 8$ in. inside diameter tubing to vent the gas directly to an exhaust hood.

\section{Equilibrium view cell}

The high-pressure equilibrium cell is one of the key components of the apparatus (see Supplemental data file). The detailed design and specifications are included in the supplemental file that is available free of charge by the pub- 
lisher. The equilibrium cell is equipped with a high-pressure gauge glass window so that the interface between vapor and liquid phases can be observed. The gauge glass is from L.J. Star Inc. Ilmadur ${ }^{\circledR}$ Borosilicate Glass I-420 brand with maximum pressure of $4000 \mathrm{psi}$ and temperature of $280{ }^{\circ} \mathrm{C}$. The equilibrium cell consists of a rectangular vessel, which is fabricated out of stainless steel and pressure tested for $24 \mathrm{~h}$ at 4000 psi without leakage. The Gore-Tex ${ }^{\circledR}$ GR PTFE gasket is used for sealing; other gasket materials are possible for use at higher temperatures. A small PTFE coated stirring bar (3.2 mm diameter $\times 12.7 \mathrm{~mm}$ ) is placed inside of the cell. An external rare-earth magnet in a slot behind the cell is raised and lowered by a pulley system and allows precision mixing throughout the cell.

\section{Volume calibration}

In order to measure the phase equilibrium data based on the mass balance, precision calibration of the volume of the cell and the lines is necessary. Calibration of both the lines and equilibrium cell was performed by the high-precision metering pump using high purity nitrogen. Nitrogen was used to calibrate due to its relatively low compressibility. Nitrogen was added to the lines or cell at the same temperature (usually room temperature). The volume needed to return the pump and lines/cell to the original pressure is the volume of the lines/cell. The calibration was repeated three times at different pressures. Our line volume was measured as $0.846 \mathrm{ml}$ and the volume of the cell is $5.716 \mathrm{ml}$. In order to minimize the volume of the lines, a short feed line with small inside diameter tubing, 0.006 in. inside diameter and $20 \mathrm{in.} \mathrm{long,} \mathrm{is} \mathrm{used.}$

The liquid volume of the cell is calibrated by correlating the height in the cell (height difference between a permanent fixed reference and the liquid height). The liquid volume was calibrated by using a $5 \mathrm{ml}$ Kimax Brand microburet with subdivision of $0.01 \mathrm{ml}$, tolerance $\pm 0.01 \mathrm{ml}$. $n$-tetradecane (99\%) was used as a calibration liquid because of its low vapor pressure and surface tension. The liquid was injected into the cell, $0.05 \mathrm{ml}$ each time, using a $12 \mathrm{in.} \mathrm{long} \mathrm{needle.}$ The height (difference) was read from the cathetometer with the telescope. The relationship between the height and the volume of the liquid is determined by a linear regression. With a $3.2 \mathrm{~mm}$ diameter $\times 12.7 \mathrm{~mm}$ PTFE stir bar installed, the minimum sample size to just cover the bar to allow accurate height measurement is approximately $0.60 \mathrm{ml}$. Thus, only a small amount of sample is needed for the measurements.

\section{EXPERIMENTAL PROCEDURES}

\section{Vapor-liquid equilibria}

The Isco pump is filled with the desired gas, such as $\mathrm{CO}_{2}$. For a typical isothermal run, the apparatus is preheated and thermally equilibrated for about $1 \mathrm{~h}$ to the desired temperature. The pump pressure is generally set constant at just above the maximum anticipated pressure and a temperature above the critical temperature, e.g., 150 bars and $60{ }^{\circ} \mathrm{C}$ for the $\mathrm{CO}_{2}$ run; this may be changed during the run. In the constant-pressure mode, the pump automatically adjusts the volume to achieve the desired pressure. The delivery lines are set above the critical temperature as well. The water bath is set at the desired temperature and the cell is put in the water bath to be preheated. The atmospheric pressure is read from a barometer, since the pump pressure transducer yields the gauge pressure.

A syringe with the liquid sample is weighed before and after injection with a long needle (12 in.) on a precision balance $( \pm 0.01 \mathrm{mg})$. The sample is carefully injected into the cell to avoid leaving droplets on the wall, which would alter the initial volume obtained from the liquid height. After injection, the cell is attached to the lines. The water bath is physically raised to immerse the entire cell in water. It generally takes approximately 30 minutes for the sample and cell to reach thermal equilibrium as confirmed in a separate experiment.

The cathetometer with telescope is set to zero on the reference line (marked on the lower portion of the cell), and then the initial liquid height is measured. The initial liquid volume is calculated based on the calibration of the height with volume. The cell is quickly flushed several times with gas at low pressure to remove any residual air or other gases. For lower pressure runs with highly soluble gases, the vacuum pump is connected to the cell by the three way valve in order to reduce the gas pressure to a minimal solubility level. The apparatus is ready to collect data after recording the initial liquid height, the initial cell pressure, temperature, each line temperature, and the pump conditions (pressure, temperature, and initial volume), as well as creating the log file to save the data in the computer.

Valve 3 (see Fig. 1), between the pump and the cell, is opened slowly to increase the cell pressure until the first desired value. The flow rate of the pump, to maintain a constant pressure while the main valve is open, is kept at less than $0.20 \mathrm{ml} / \mathrm{min}$ to prevent any large $P V T$ disturbances in temperature. After valve 3 is closed, the pump is given time to equilibrate until the flow rate reads zero, then the final volume of the pump is recorded. The difference of the volume is used to compute the mass of $\mathrm{CO}_{2}$ injected into the cell by the computed density of the gas. During the pressurization, the stir bar inside of the cell is used to mix the vapor phase and liquid phase by stirring the interface to accelerate the mass transfer process into the liquid sample. With vigorous mixing, equilibrium is often reached after approximately $30 \mathrm{~min}$; longer times are needed with more viscous liquids. When equilibrium is reached, all variables are recorded and then entered into the spreadsheet (EXCEL) to compute the properties and associated error analysis.

\section{Mixture critical points}

The mixture critical points can be determined by careful observation of the liquid-vapor interface. As the vapor-liquid critical point usually occurs in organic liquids that have expanded several hundred percent of the initial volume, lower sample volumes/mass are loaded, here $\sim 0.6 \mathrm{ml}$. The gas is injected into the system while mixing until near the critical point in pressure. The gas is then very slowly injected $(<0.1 \mathrm{bar} / \mathrm{min})$ while stirring until the disappearance of the interface which is often preceded by "critical opalescence.", 
In order to see the phenomena clearly (not near the top of the cell), it may take several runs to find an appropriate initial loading. As the critical mixture is in one phase, the mole fraction is simply the total pump amount delivered to the cell and the initial mass of liquid.

\section{Solid-liquid-vapor equilibrium}

For binary systems, the pressure and temperature in which solid, liquid, and vapor coexist in equilibrium may be determined. First, solid is loaded into the cell; this may require dissolution into a volatile solvent, injection into the cell, followed by sufficient vacuum. The system is pressurized and heated until the solid completely melts. The temperature is then reduced until the first appearance of a crystal. This procedure is called the method of "first freezing." The composition at this point is often difficult to measure as the mass balance procedure requires accurate measures of initial volume; the compound of interest in this case is a solid until it is induced to melt with the compressed gas.

For ternary systems, the point at which a solid is precipitated from a liquid solution using the compressed gas as an antisolvent is the solid-liquid-vapor equilibrium. The knowledge of this point is very important for particle production methods that are beginning to be used by the pharmaceutical industry. ${ }^{5}$ The procedure is similar to the VLE experiments, except that the initial liquid has a certain concentration of a solid component. For an isotherm run, the gas, such as $\mathrm{CO}_{2}$, is continuously injected into the cell with the liquid solution, until the first appearance of a solid particle, which is assumed to have negligible mass compared with the total solution. The concentration of all components can then be measured. The pressure and composition will change with different initial concentrations of the solid in the liquid.

\section{Dew points}

This apparatus can also be used for measuring dew points. However, it is often difficult to perform the measurements at constant temperature. First the gas is added into the cell and mixed with a small amount of liquid to make a solution of known overall concentration. The temperature is raised until one phase is formed and then cooled until the first drop of liquid appears in the cell. The drop is assumed to have negligible mass, thus the composition is determined from the initial loading of gas and liquid. More gas can be added to the cell and the procedure is repeated.

\section{Vapor-liquid-liquid equilibrium}

Vapor-liquid-liquid equilibrium can occur near the vapor pressure of the pure gas and even extend to temperatures above the critical point of the pure gas. At this point, a liquid phase rich in the organic liquid $\left(L_{1}\right)$, a liquid phase rich in the compressed gas $\left(L_{2}\right)$, and a vapor phase rich in the compressed gas can exist. VLLE data can terminate at an upper critical end point (UCEP) at higher temperatures. In addition, type IV systems according to the classification of Scott and van Konynenburg $^{22,23}$ can have a break in the VLLE line at a lower temperature upper critical endpoint. The VLLE composition for each of the liquid phases is determined by two
TABLE I. The phase equilibrium data of carbon dioxide $+n$-decane at $71.1^{\circ} \mathrm{C}$.

\begin{tabular}{ccccc}
\hline \hline $\begin{array}{c}\text { Pressure } \\
\text { (bar) }\end{array}$ & $\begin{array}{c}\text { Mole fraction } \\
\text { of } \mathrm{CO}_{2} \text { in } \\
\text { decane }\end{array}$ & $\begin{array}{c}\text { Density } \\
\left(\mathrm{g} / \mathrm{cm}^{3}\right)\end{array}$ & $\begin{array}{c}\text { Volume } \\
\text { expansion } \\
\left(V-V^{\circ}\right) / V^{\circ}\end{array}$ & $\begin{array}{c}\text { Molarity } \\
(\mathrm{mol} / \mathrm{l})\end{array}$ \\
\hline 17.26 & $0.1284 \pm 0.0010$ & $0.6758 \pm 0.0007$ & $0.0401 \pm 0.0005$ & $0.669 \pm 0.006$ \\
33.68 & $0.2669 \pm 0.0009$ & $0.6861 \pm 0.0008$ & $0.0902 \pm 0.0005$ & $1.578 \pm 0.008$ \\
56.24 & $0.4127 \pm 0.0011$ & $0.6888 \pm 0.0009$ & $0.1881 \pm 0.0005$ & $2.794 \pm 0.012$ \\
73.26 & $0.5246 \pm 0.0012$ & $0.6948 \pm 0.0011$ & $0.2978 \pm 0.0005$ & $4.017 \pm 0.019$ \\
87.43 & $0.6209 \pm 0.0016$ & $0.7069 \pm 0.0017$ & $0.4329 \pm 0.0005$ & $5.401 \pm 0.036$ \\
101.15 & $0.7023 \pm 0.0023$ & $0.7064 \pm 0.0034$ & $0.6459 \pm 0.0006$ & $6.771 \pm 0.075$ \\
\hline \hline
\end{tabular}

individual runs with different initial loadings of the organic liquid. If the phase of the organic liquid of interest, here labeled $L_{1}$, is to be studied, the cell is injected with a large amount (by volume) of the liquid sample, and the gas (e.g., $\mathrm{CO}_{2}$ ) is continuously added to the system just until a droplet or very thin film of the $L_{2}$ layer appears; the phase is assumed to have negligible mass, and the composition of the mostly organic liquid can be determined. To determine the composition of the $L_{2}$ layer, a small amount of the liquid sample, $L_{1}$, is added into the cell. Gas is added until a large amount of the $L_{2}$ phase forms and the $L_{1}$ phase just dissolves completely into the $L_{2}$ phase or only a small fraction of the original $L_{1}$ phase remains. The composition of the $L_{2}$ phase can then be determined assuming all of the loaded $L_{1}$ phase dissolved into the $L_{2}$ phase, the density of the $L_{2}$ to be that of the pure saturated liquid at the system temperature, and knowing the volume of the $L_{2}$-phase. It should be noted that for many binary systems, the $L_{2}$ phase is often mostly the gaseous species $(95+\%)$ and errors in the organic liquid component in $L_{2}$ will often have larger errors. When the three phase equilibrium is reached, the upper and lower critical endpoints (UCEP and LCEP, respectively) can be determined by increasing or decreasing the temperature until one of the liquid phases disappears.

\section{APPARATUS VERIFICATION}

The phase equilibrium data of carbon dioxide in $n$-decane at $71.1^{\circ} \mathrm{C}$ is given in Table I. Figure 2(a) illustrates the $P-x$ phase equilibrium of $\mathrm{CO}_{2}(99.99 \%$ purity) and $n$-decane (with purity of $99.9 \%$ ) binary system. As can be seen in the figure, the experimental data of this setup are in excellent agreement with literature data of Shaver et al. ${ }^{24}$ and Nagarajan, and Robinson, Jr., ${ }^{25}$ which were measured by an analytical method. They sampled the liquid phase from the equilibrium cell and analyzed using a gas chromatograph (GC) for composition. Figure 2(b) compares between our work and Reamer and Sage ${ }^{26}$ and Jennings and Schucker, ${ }^{27}$ which used the synthetic method; again, our data agree very well. Reamer and Sage $^{26}$ used a gravimetric method by weighing the $\mathrm{CO}_{2}$ and determined $n$-decane from volumetric measurements. Jennings and Schucker ${ }^{27}$ used a variablevolume cell apparatus and a flow apparatus. They weighed the $n$-decane and $\mathrm{CO}_{2}$, and then computed the solubility. Figure 3 illustrates the density data of $n$-decane and $\mathrm{CO}_{2}$ in the liquid phase. The experimental data have a very good 

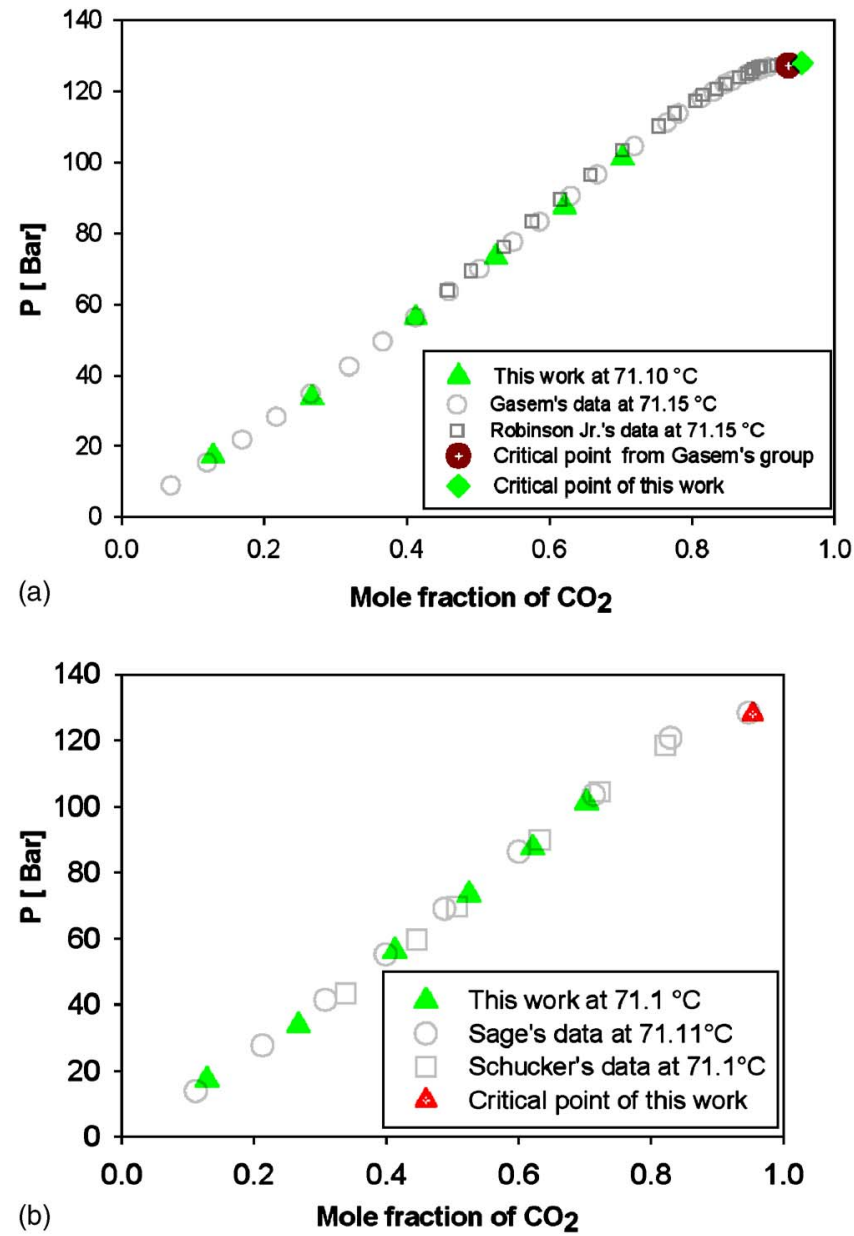

FIG. 2. (Color online) (a) Phase equilibrium data of $n$-decane/ $/ \mathrm{CO}_{2} 71^{\circ} \mathrm{C}$ with literature data using the analytical method: data of Shaver et al. (Ref. 24) and Nagarajan and Robinson (Ref. 25). (b) Phase equilibrium data of $n$-decane $/ \mathrm{CO}_{2}$ at $71{ }^{\circ} \mathrm{C}$ with literature data using the synthetic method: data of Reamer and Sage (Ref. 26), Jennings and Schucker (Ref. 27).

correlation to the literature data of Shaver et al. ${ }^{24}$ and Nagarajan and Robinson. ${ }^{25}$ Their density data were obtained by using a densitometer. The mixture critical point for $n$-decane and $\mathrm{CO}_{2}$ at $71.1{ }^{\circ} \mathrm{C}$ is 127.9 bars and the mole fraction of $\mathrm{CO}_{2}$ is $95.34 \%$, compared to the literature data (127.2 bars and $\left.93.5 \% \mathrm{CO}_{2}\right)$ at $71.15{ }^{\circ} \mathrm{C}^{24}$ The difference of $\mathrm{CO}_{2}$ composition is less than $2 \%$, and the critical pressure difference is less than 1 bar.

The solubility of $\mathrm{CO}_{2}$ in a room-temperature ionic liquid



FIG. 3. (Color online) The mixture density data of $n$-decane/ $\mathrm{CO}_{2}$ at $71{ }^{\circ} \mathrm{C}$ with literature data of Shaver et al. (Ref. 24) Robinson and Nagarajan Jr. (Ref. 25).
TABLE II. The phase equilibrium data of carbon dioxide $+[\mathrm{HMim}]\left[\mathrm{Tf}_{2} \mathrm{~N}\right]$ at $60.0^{\circ} \mathrm{C}$.

\begin{tabular}{ccccc}
\hline \hline $\begin{array}{c}\text { Pressure } \\
\text { (bar) }\end{array}$ & $\begin{array}{c}\text { Mole fraction } \\
\text { of } \mathrm{CO}_{2} \text { in } \\
{[\mathrm{HMim}]\left[\mathrm{Tf}_{2} \mathrm{~N}\right]}\end{array}$ & $\begin{array}{c}\text { Density } \\
\left(\mathrm{g} / \mathrm{cm}^{3}\right)\end{array}$ & $\begin{array}{c}\text { Molality } \\
(\mathrm{mol} / \mathrm{kg})\end{array}$ & $\begin{array}{c}\text { Volume } \\
\text { expansion } \\
\left(V-V_{0}\right) / V_{0}\end{array}$ \\
\hline 24.35 & $0.2768 \pm 0.0018$ & $1.287 \pm 0.001$ & $0.855 \pm 0.008$ & $0.0439 \pm 0.0005$ \\
46.29 & $0.4791 \pm 0.0012$ & $1.282 \pm 0.001$ & $2.056 \pm 0.010$ & $0.1014 \pm 0.0005$ \\
64.58 & $0.5454 \pm 0.0009$ & $1.256 \pm 0.001$ & $2.682 \pm 0.010$ & $0.1528 \pm 0.0005$ \\
84.10 & $0.6287 \pm 0.0011$ & $1.250 \pm 0.001$ & $3.784 \pm 0.018$ & $0.2085 \pm 0.0005$ \\
108.25 & $0.7000 \pm 0.0019$ & $1.251 \pm 0.002$ & $5.214 \pm 0.048$ & $0.2726 \pm 0.0006$ \\
122.44 & $0.7344 \pm 0.0022$ & $1.261 \pm 0.003$ & $6.180 \pm 0.069$ & $0.3057 \pm 0.0006$ \\
\hline \hline
\end{tabular}

(organic salt) is used to verify the apparatus at higher pressures. The ionic liquid, 1-hexyl-3-methylimidazolium bis(trifluoromethylsulfonyl)imide ([HMim] $\left.]\left[\mathrm{Tf}_{2} \mathrm{~N}\right]\right)$, was synthesized in our laboratory following standard procedures. ${ }^{28}$ $[\mathrm{HMim}]\left[\mathrm{Tf}_{2} \mathrm{~N}\right]$, as an ionic compound, has nearly no vapor pressure and no measurable solubility in $\mathrm{CO}_{2}$. The phase equilibrium data of $\mathrm{CO}_{2}$ in $[\mathrm{HMim}]\left[\mathrm{Tf}_{2} \mathrm{~N}\right]$ at $60.0^{\circ} \mathrm{C}$ is given in Table II. The solubility data of $\mathrm{CO}_{2}$ in [HMim] $\left[\mathrm{Tf}_{2} \mathrm{~N}\right]$ are shown in Fig. 4, and they match the data from Kumelan et al. ${ }^{29}$ and Aki et al. ${ }^{30}$ very well. For Kumelan et al., the visual synthetic method was used. ${ }^{31}$ After a known amount of mixture is put in the equilibrium cell, the pressure or temperature is adjusted until the phase change is observed.

For the determination of gas solubility, this apparatus is based on an assumption of little or no liquid dissolution in the vapor phase. Comparison with literature data does not allude to any meaningful difference. However, the veracity of this assertion deserves further discussion. By using the dew point data for $\mathrm{CO}_{2} / n$-decane from literature sources, ${ }^{25}$ an estimate of the mass transferred from the liquid phase to the vapor phase may be computed and is illustrated in Table III. For instance, at 103.34 bars at $71.15^{\circ} \mathrm{C}$, the dew point composition is 0.008 mole fraction $n$-decane. By computing the molarity with the vapor density and using the typical volumes of the vapor phase found in our experiments, only $\sim 0.13 \%$ of the original (loaded moles) of $n$-decane would be removed from the liquid phase to the vapor phase. Thus, the loss can be considered negligible. From simulation of the more volatile systems, the reported accuracies can be maintained with dew point compositions less than $10 \%$.

\section{CONCLUSION}

A new apparatus is presented for measuring the highpressure phase equilibrium up to 300 bars and $150{ }^{\circ} \mathrm{C}$. The

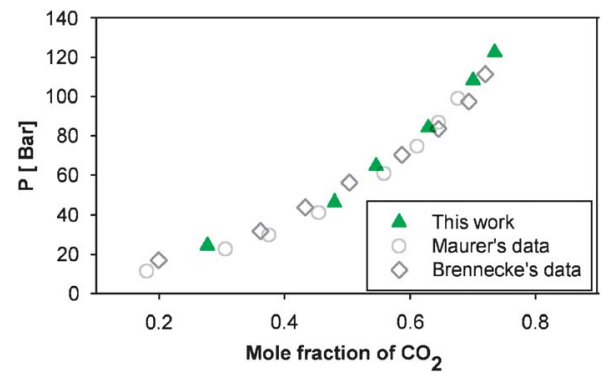

FIG. 4. (Color online) Phase equilibrium data of $\mathrm{CO}_{2}$ in $[\mathrm{HMim}]\left[\mathrm{Tf}_{2} \mathrm{~N}\right]$ at $60{ }^{\circ} \mathrm{C}$ with the data from Kumelan et al. (Ref. 29) and Aki et al. (Ref. 30). 
TABLE III. Estimate of the amount of $n$-decane transferred to the $\mathrm{CO}_{2}$ phase at $71.1^{\circ} \mathrm{C}$.

\begin{tabular}{ccccc}
\hline \hline $\begin{array}{c}\text { Pressure } \\
\text { (bar) }\end{array}$ & $\begin{array}{c}\text { Mole fraction } \\
\text { of decane } \\
\text { in } \mathrm{CO}_{2}{ }^{\mathrm{a}}\end{array}$ & $\begin{array}{c}\text { Molarity } \\
(\mathrm{mM})\end{array}$ & $\begin{array}{c}\text { Moles of } \\
\text { decane } \\
\times 10^{5}\end{array}$ & $\begin{array}{c}\text { Percentage of } \\
\text { initial decane in } \\
\mathrm{CO}_{2} \text { phase }(\%)\end{array}$ \\
\hline 35.06 & 0.994 & 8.19 & 1.8 & 0.12 \\
46.04 & 0.995 & 9.39 & 1.9 & 0.13 \\
71.83 & 0.996 & 13.29 & 2.2 & 0.14 \\
71.97 & 0.995 & 16.62 & 2.7 & 0.18 \\
83.54 & 0.995 & 20.61 & 2.7 & 0.18 \\
90.57 & 0.994 & 27.95 & 2.9 & 0.19 \\
103.45 & 0.992 & 46.26 & 2.0 & 0.13 \\
\hline \hline
\end{tabular}

${ }^{\mathrm{a}}$ The dew points data are from Nagarajan and Robinson, Jr. (Ref. 25).

construction and operation of the apparatus are described in detail and does not use mercury. The apparatus is capable of a large variety of experiments for different equilibria and properties, e.g., VLE, SLV, VLLE, mixture critical points, etc. It is easy to use, very accurate, and does not need any system-specific calibration. Data from this apparatus are in excellent agreement with literature reports using two very different substrates: an $n$-alkane and an ionic liquid.

\section{ACKNOWLEDGMENTS}

Financial support was provided by the National Science Foundation: NSF-ERC Center for Environmentally Beneficial Catalysis (EEC-0310689) and (CTS-0626313), the Tertiary Oil Recovery Project (TORP) of the University of Kansas, and the DOT:KU Transportation Research Institute (TRI) (DOT No. DT0S59-06-G-00047). We would like to especially thank Mr. Scott Ramskill (of TORP) for help in the design and manufacturing of the apparatus.

${ }^{1}$ F. Van Bergen, J. Gale, K. J. Damen, and A. F. B. Wildenborg, Energy 29, 1611 (2004).

${ }^{2}$ M. Bocevska and H. Sovova, J. Supercrit. Fluids 40, 360 (2007).

${ }^{3}$ S. Machmudah, A. Sulaswatty, M. Sasaki, M. Goto, and T. Hirose, J. Supercrit. Fluids 39, 30 (2006).

${ }^{4}$ M. C. McLeod, M. Anand, C. L. Kitchens, and C. B. Roberts, Nano Lett. 5, 461 (2005).
${ }^{5}$ G. A. Sacha, W. J. Schmitt, and S. L. Nail, Pharm. Dev. Technol. 11, 187 (2006).

${ }^{6}$ B. Y. Shekunov, S. Bristow, A. H. L. Chow, L. Cranswick, D. J. W. Grant, and P. York, Cryst. Growth Des. 3, 603 (2003).

${ }^{7}$ A. Ahosseini, W. Ren, and A. M. Scurto, Chem. Today/Chimica Oggi 25, 40 (2007).

${ }^{8}$ P. G. Jessop and B. Subramaniam, Chem. Rev. (Washington, D.C.) 107, 2666 (2007)

${ }^{9}$ M. S. John and J. I. Siepmann, J. Chem. Phys. 121, 1525 (2004).

${ }^{10}$ C. H. Turner and E. G. Keith, J. Chem. Phys. 119, 6057 (2003).

${ }^{11}$ M. P. Anisimov, J. A. Koropchak, A. G. Nasibulin, and L. V. Timoshina, J. Chem. Phys. 109, 10004 (1998).

${ }^{12}$ R. Dohrn and G. Brunner, Fluid Phase Equilib. 106, 213 (1995).

${ }^{13}$ H. D. K. Baehr, F. Klabasa, and R. Scharf, Int. J. Thermophys. 10, 577 (1989).

${ }^{14}$ M. Glaser, C. J. Peters, H. J. van der Kooi, and R. N. Lichtenthaler, J. Chem. Thermodyn. 17, 803 (1985).

${ }^{15}$ J. P. Kohn, Ph.D. thesis, University of Kansas, 1956.

${ }^{16}$ N. C. Huie, Ph.D. thesis, University of Notre Dame, 1972.

${ }^{17}$ A. M. Scurto, Ph.D. thesis, University of Notre Dame, 2002.

${ }^{18}$ D. J. Fall and K. D. Luks, J. Chem. Eng. Data 29, 413 (1984).

${ }^{19}$ E. W. Lemmon, M. L. Huber, and M. O. McLinden, NIST Reference Fluid Thermodynamic and Transport Properties, REFPROP Version 8.0, Gaithersburg, MD, 2007.

${ }^{20}$ R. Span and W. Wagner, J. Phys. Chem. Ref. Data 25, 1509 (1996).

${ }^{21}$ C. P. Hicks and C. L. Young, Chem. Rev. (Washington, D.C.) 75, 119 (1975).

${ }^{22}$ R. L. Scott and P. H. Van Konynenburg, Discuss. Faraday Soc. 49, 87 (1970).

${ }^{23}$ P. H. Van Konynenburg and R. L. Scott, Philos. Trans. R. Soc. London, Ser. A 298, 495 (1980).

${ }^{24}$ R. D. Shaver, R. L. Robinson, and K. A. M. Gasem, Fluid Phase Equilib. 179, 43 (2001).

${ }^{25}$ N. Nagarajan and R. L. Robinson, Jr., J. Chem. Eng. Data 31, 168 (1986).

${ }^{26}$ H. H. Reamer and B. H. Sage, J. Chem. Eng. Data 8, 508 (1963).

${ }^{27}$ D. W. Jennings and R. C. Schucker, J. Chem. Eng. Data 41, 831 (1996).

${ }^{28}$ P. Bonhôte, A.-P. Dias, N. Papageorgiou, K. Kalyanasundaram, and M. Graetzel, Inorg. Chem. 35, 1168 (1996).

${ }^{29}$ J. Kumelan, A. Perez-Salado Kamps, D. Tuma, and G. Maurer, J. Chem. Thermodyn. 38, 1396 (2006).

${ }^{30}$ S. N. V. K. Aki, B. R. Mellein, E. M. Saurer, and J. F. Brennecke, J. Phys. Chem. B 108, 20355 (2004).

${ }^{31}$ J. Xia, M. Joedecke, A. Perez-Salado Kamps, and G. Maurer, J. Chem. Eng. Data 49, 1756 (2004).

${ }^{32}$ See EPAPS Document No. E-RSINAK-78-019712 for a diagram of the high-pressure viewcell and a detailed error analysis for the entire apparatus. This document can be reached through a direct link in the online article's HTML. reference section or via the EPAPS homepage (http:// www.aip.org/pubservs/epaps.html). 